\title{
Laryngeal damage due to an unexpectedly large and inappropriately designed cuffed pediatric tracheal tube in a 13-month-old child
}

\author{
[Lésion laryngée causée par un tube trachéal pédiatrique à ballonnet, mal conçu \\ et trop grand, utilisé chez un enfant de 13 mois]
}

Claudia M. Dillier MD, ${ }^{*}$ Daniel Trachsel MD, $†$ Werner Baulig MD, $\ddagger$ Claudine Gysin MD,, $\mathfrak{S}$ Andreas C. Gerber MD, ${ }^{*}$ Markus Weiss MD*

Purpose: To present a case of laryngeal damage in an infant caused by a too large and inappropriately designed cuffed tracheal tube.

Clinical features: A 13-month-old child undergoing cardiac surgery was intubated with an uncuffed endotracheal tube with an internal diameter (ID) of $4.0 \mathrm{~mm}$. Because of an important air leak around the tracheal tube during mechanical ventilation, a cuffed endotracheal tube ID $4.0 \mathrm{~mm}$ was inserted. The air leak with the tube cuff not inflated was acceptable at $25 \mathrm{~cm} \mathrm{H}_{2} \mathrm{O}$ airway pressure. After extubation on the third postoperative day, the patient showed increasing stridor and respiratory deterioration. Fibreoptic laryngoscopy of the spontaneously breathing patient showed a large intra-laryngeal web. After surgical removal of the web, the child rapidly recovered and was discharged from the hospital on the 12th postoperative day.

Inspection of the $4.0 \mathrm{~mm}$ (ID) cuffed tracheal tube revealed a cuff positioned inappropriately high and an increase of $0.7 \mathrm{~mm}$ in outer tube diameter compared to the $4.0 \mathrm{~mm}$ (ID) uncuffed tracheal tube from the same manufacturer. The tube cuff is likely to be situated within the larynx when placed in accordance to insertion depth formulas or radiological criteria, as used for uncuffed tracheal tubes in children.

Conclusion: The larger than expected tracheal tube with its intralaryngeal cuff position in a 13-month-old child likely caused mucosal damage and an inflammatory reaction within the larynx resulting in granulation tissue formation and fibrous healing around the tracheal tube.
Objectif : Présenter un cas de lésion laryngée causée, chez un enfant, par un tube trachéal à ballonnet, trop grand et mal conçu.

Éléments cliniques : Un enfant de 13 mois devant subir une intervention cardiaque a été intubé avec un tube endotrachéal sans ballonnet d'un diamètre interne (DI) de 4,0 mm. Étant donné l'importante fuite d'air autour du tube trachéal pendant la ventilation mécanique, un tube endotrachéal à ballonnet de 4,0 mm de DI a été inséré. La fuite d'air notée autour du ballonnet non gonflé était acceptable pour une pression des voies aériennes de $25 \mathrm{~cm} \mathrm{H}_{2} \mathrm{O}$. Après l'extubation, au troisième jour postopératoire, le patient a présenté un stridor croissant et une détérioration respiratoire. La fibroscopie du larynx pendant la respiration spontanée a montré une grande membrane intralaryngée. Après le retrait chirurgical de la membrane, l'enfant s'est rapidement rétabli et a quitté l'hôpital le $12^{\mathrm{e}}$ jour.

L'examen du tube à ballonnet de 4,0 mm a révélé un ballonnet placé trop haut et une augmentation de 0,7 mm du diamètre extérieur du tube, comparé au tube sans ballonnet de $4,0 \mathrm{~mm}$ réalisé par le même fabricant. Le ballonnet se situe à l'intérieur du larynx quand on place le tube selon les formules d'insertion ou les critères radiologiques, comme on le fait avec les tubes trachéaux sans ballonnets chez les enfants.

Conclusion : Le tube trachéal, plus gros que prévu, placé dans le larynx dans la position indiquée pour un tube à ballonnet chez un enfant de 13 mois, a causé une lésion de la muqueuse et une réaction inflammatoire dans le larynx, ce qui a entraîné la formation de tissu de granulation et une cicatrisation fibreuse autour du tube trachéal.

From the Departments of Anesthesia, ${ }^{*}$ Intensive Care and Neonatology, $\dagger$ and Otorhinolaryngology, $\mathfrak{S}$ University Children's Hospital; and the Institute of Anesthesiology, $\ddagger$ University Hospital, Zurich, Switzerland.

Address correspondence to: Dr. Markus Weiss, Department of Anesthesia, University Children's Hospital, Steinwiesstrasse 75, CH-8032

Zurich. Phone: +41 l 26671 11; Fax: +41 12667994 ; E-mail: markus.weiss@kispi.unizh.ch

Accepted for publication May 12, 2003.

Revision accepted October 22, 2003. 
I $\mathrm{N}$ the last decade, the use of cuffed tracheal tubes in children younger than eight to ten years has been reported by several authors. ${ }^{1-3}$ The advantages mentioned are improved efficiency of ventilation, reduced atmospheric pollution, more reliable end-tidal $\mathrm{CO}_{2}$ monitoring, ability to use low flow anesthesia, reduced need to replace an ill-fitting tracheal tube and a decreased use of too large uncuffed tubes, the main reason for subglottic stenosis. ${ }^{4,5}$ However, serious concerns have been raised regarding inadvertent cuff hyperinflation causing airway damage with the risk of post-extubation morbidity (stridor, subglottic stenosis). ${ }^{5-7}$ We report a case of laryngeal damage in a child due to a too large and inadequately designed cuffed tracheal tube.

\section{Case report}

A 13-month-old boy (weight $7.4 \mathrm{~kg} /$ length $69 \mathrm{~cm}$ ) with multiple ventricular septal defects and an anomalous return of the right upper pulmonary vein into the superior vena cava was scheduled for cardiac surgery. One year earlier, a coarctation of the aorta had been repaired and a pulmonary artery banding inserted. Half a year later it had been necessary to dilate the pulmonary banding. On these occasions, the boy never displayed any sings of stridor or respiratory obstruction.

After $i v$ induction of anesthesia and muscle paralysis the trachea was intubated with an uncuffed tracheal tube internal diameter (ID) $4.0 \mathrm{~mm}$ (Rüschelit, Rüsch, Kernen, Germany). Direct laryngoscopy was uneventful without detection of laryngeal abnormalities. Because of an important air leak around the uncuffed tracheal tube during mechanical ventilation, the tracheal tube was replaced. A cuffed tracheal tube ID $4.0 \mathrm{~mm}$ (Rüsch Super Safety Clear, Rüsch, Kernen, Germany) was inserted with the cuff placed below the vocal cords. The air leak with the tube cuff not inflated was acceptable at $25 \mathrm{~cm} \mathrm{H}_{2} \mathrm{O}$ airway pressure. Ventilation and oxygenation during surgery and in the cardiac intensive care unit were unremarkable. The boy was transferred to the pediatric intensive care unit (PICU) of the University Children's Hospital on the second postoperative day.

On PICU admission the child was intubated nasally with the tracheal tube cuff fully deflated. According to our PICU guidelines for the use of cuffed endotracheal tubes, the cuff was set at ambient pressure by connecting a syringe without plunger to the pilot balloon. After weaning from mechanical ventilation the child was extubated on the third postoperative day. Shortly after extubation he developed stridor with increasing oxygen requirement and laboured breath-

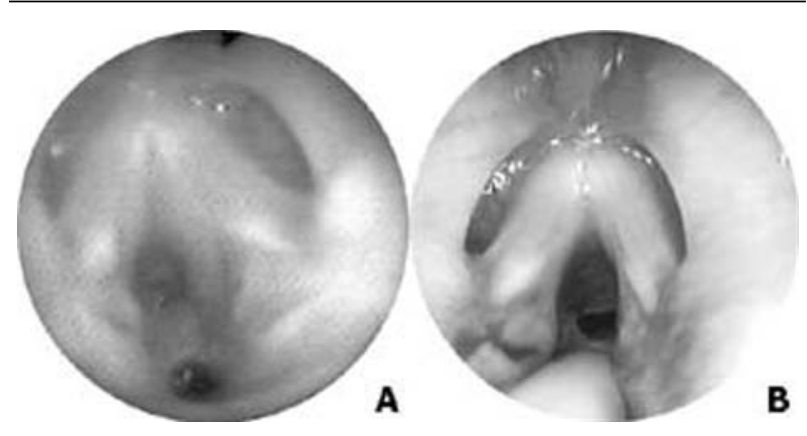

FIGURE 1 Left, fibreoptic laryngoscopy revealed symmetrical vocal cord activity with an intra-laryngeal fibrous web below the glottic level. The posterior glottic opening corresponds to the initial endotracheal tube pathway. Right, rigid laryngoscopy after nasotracheal intubation with a $2.5 \mathrm{~mm}$ uncuffed endotracheal tube through the posterior glottic opening.

ing. Because of persisting stridor and respiratory distress, a nasal fibreoptic laryngoscopy through the face mask was performed in the PICU on the fifth postoperative day. It revealed an intra-laryngeal transverse web which obstructed the glottic opening (Figure 1, left; Video, available as additional material at www.cjajca.org). On the same day, the boy was transferred to the operating theatre for surgical removal of the laryngeal web. Direct laryngoscopy with a no. 1 Miller blade laryngoscope and a rigid endoscope confirmed the diagnosis of laryngeal web. Tracheal intubation was achieved with an uncuffed tube ID $2.5 \mathrm{~mm}$ through the posterior glottic opening (Figure 1, right). The laryngeal web was successfully removed by the pediatric otorhinolaryngologist. At the end of the intervention the child was extubated and transferred to the PICU. At the time of transfer stridor had significantly decreased, the child had minimal respiratory distress and was able to maintain oxygen saturation The patient was later transferred to a regular ward and was discharged on the 12th postoperative day. Three weeks later, he presented for an ambulatory control by the otorhinolaryngologist. The boy was free of respiratory symptoms and showed no signs of residual laryngeal pathology.

\section{Discussion}

Cuffed tracheal tube sizes in children are normally selected in accordance to the modified Cole's formula which relates uncuffed tube size to age (i.e., ID $(\mathrm{mm})$ $=($ age $/ 4)+4.0)$ while the tube size is reduced by 0.5 $\mathrm{mm}$ or $1.0 \mathrm{~mm}$ to allow for the presence of the cuff 


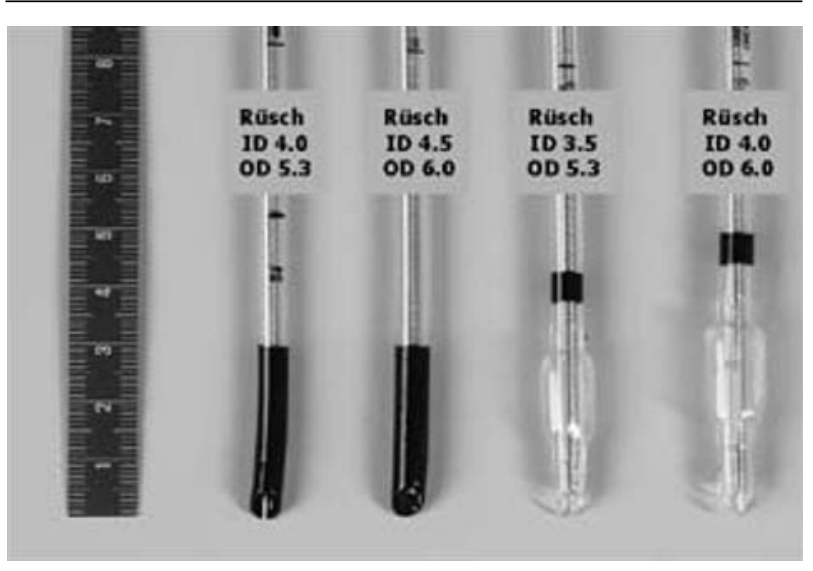

FIGURE 2 Comparison of the 4.0 and $4.5 \mathrm{~mm}$ uncuffed tracheal tubes (Rüschelit, Rüsch, Kernen, Germany - outer diameter (OD) $5.3 / 6.0 \mathrm{~mm}$ ) with the 3.5 and $4.0 \mathrm{~mm}$ cuffed tracheal tubes (Rüsch Super Safety Clear, Rüsch, Kernen, Germany - OD $5.3 / 6.0 \mathrm{~mm})$.

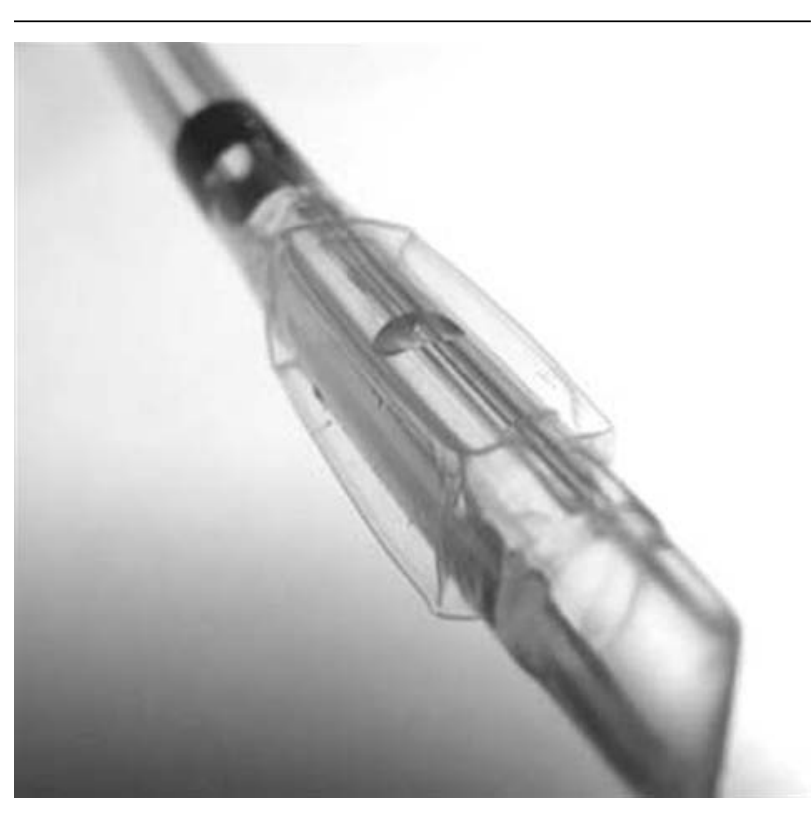

FIGURE 3 Active deflation from the tracheal tube cuff leads to sharp folds and edges. (ID $4.0 \mathrm{~mm}$ Rüschelit ${ }^{\circledR}$ Super Safety Clear tube). (i.e., Motoyama, ID $(\mathrm{mm})=($ age $/ 4)+3.5$; Khine et al., ID $(\mathrm{mm})=($ age $/ 4)+3.0))^{2,8,9}$ In children under the age of two years these equations are not applicable, and tube size ID $3.0 \mathrm{~mm}$ for full-term neonates and ID $3.5 \mathrm{~mm}$ for one-year-old children are recommended according to specific tables. ${ }^{1,10}$ The cuffed tracheal tube selected in this case would seem to be large for a 13-month-old child and a 3.5-mm ID cuffed tracheal tube would have been more appropriate. However, an unexpectedly large air leak around the uncuffed tracheal tube ID $4.0 \mathrm{~mm}$, resulting in inadequate ventilation, necessitated a tube change to a larger ID $4.5 \mathrm{~mm}$ uncuffed or a cuffed ID $4.0 \mathrm{~mm}$ tracheal tube. This is often observed in children with a history of previous mechanical ventilation in the PICU. Thus, the selection of an ID 4.0 cuffed tracheal tube in this patient was appropriate and corresponded to Motoyama's recommendation to choose an ID 0.5 smaller than the uncuffed tracheal tube. In addition, smaller tracheal tubes lead to higher airway resistance, increased work of breathing and difficult tracheobronchial suctioning. Unfortunately, the outer diameter (OD) of the selected cuffed Rüschelit tracheal tube ID 4.0 was, unexpectedly, $0.7 \mathrm{~mm}$ larger (OD: 6.0 $\mathrm{mm}$ ) than the Rüsch uncuffed tracheal tube ID 4.0 (OD: $5.3 \mathrm{~mm}$ ) inserted initially. This resulted in a fit of the tracheal tube within the cricoid ring with a minimal air leak at $25 \mathrm{~cm} \mathrm{H}_{2} \mathrm{O}$, the tube cuff not being inflated. Mucosal airway edema after cardiopulmonary bypass probably led to a tight fit of the larger than expected tube within the airway so that, on PICU admission, air leak around the tracheal tube was absent, even with the cuff being actively deflated.

Active deflation of a tube cuff results in sharp folds and edges of the cuff membrane which lead to mucosal damage within the airway by "cutting" the mucosa with every tube movement during the respiratory cycle (Figure 3). In addition, as demonstrated in Figure 2 the cuff of the Rüsch cuffed tube ID $4.0 \mathrm{~mm}$ is positioned higher on the tube shaft $(33 \mathrm{~mm})$ compared to the level of the depth markings of the ID 4.0 $\mathrm{mm}$ or ID $4.5 \mathrm{~mm}$ uncuffed tube $(30 \mathrm{~mm})$ of the same manufacturer. It could be considered that the high position of the cuff results from the inappropriate selection of tube size, however, in a similar fashion, the cuff of the ID $3.5 \mathrm{~mm}$ Rüsch tube is positioned too high $(30 \mathrm{~mm})$ compared to an ID 4.0 or ID 4.5 $\mathrm{mm}$ uncuffed tracheal tube (Figure 2).

Although the tube cuff was placed initially below the vocal cords, it is likely that, afterwards, the cuff became displaced into a laryngeal position by adjusting depth of insertion according to radiological criteria, as used for uncuffed tracheal tubes. Position was confirmed by the postoperative chest radiograph, 
demonstrating the tracheal tube in a mid-tracheal position. In addition, during cardiac surgery with extension of the head and neck, the cuff becomes positioned more cephalad. Thus, we hypothesize that the sharp cuff folds within the larynx led to mucosal damage and an inflammatory reaction within the larynx, resulting in granulation tissue formation, fibrous transformation and intra-laryngeal web formation. ${ }^{11}$

Lessons are to be learned for both anesthesiologists and manufacturers: (1) Many anesthesiologists may not be aware of differences in outer tube diameter between uncuffed and cuffed tracheal tubes, in particular those rarely caring for children. This can lead to the unnecessary insertion of ill-fitting tubes and the need to change the tube while risking airway damage. Because differences occur even in tubes provided by the same manufacturer, age-ranges for the selection of uncuffed, cuffed or wire-inforced tracheal tubes should be provided by the manufacturer or the anesthesia department. (2) The appropriate selection of cuffed tracheal tubes in infants and children necessitates an air leak at $20 \mathrm{~cm} \mathrm{H}_{2} \mathrm{O}$ with the cuff not inflated, if not, the tube should be changed to a smaller size. (3) Active deflation of the endotracheal tube cuff must be avoided except prior to tracheal extubation and must not be used to achieve an air leak in an overly large tube, otherwise mucosal airway damage may occur. If it is decided to keep the tube cuff not inflated during surgery or in the ICU, cuff pressure should be released and set to ambient pressure by a cuff pressure manometer or a syringe without plunger. (4) Anesthesiologists should be aware that not all available cuffed pediatric tubes can be assumed to be without flaw. To select a cuff that will have the least chance of causing airway damage, OD and cuff position should be checked and compared to the OD of uncuffed tubes and to the estimated length of the trachea. Depth markings should be compared with those of the next size uncuffed tracheal tube. $^{12}$ (5) Manufacturers should revise the design of their cuffed tubes in accordance to age-related anatomical measurements in particular regarding height of the cuff position and depth markings.

In conclusion, the larger than expected tracheal tube with its intra-laryngeal cuff position in a 13month-old child likely caused mucosal damage and an inflammatory reaction within the larynx resulting in granulation tissue formation and fibrous healing around the tracheal tube.

\section{References}

1 Deakers TW, Reynolds G, Stretton M, Newth CJ. Cuffed endotracheal tubes in pediatric intensive care. J Pediatr 1994; 125: 57-62.
2 Khine HH, Corddry DH, Kettrick RG, et al. Comparison of cuffed and uncuffed endotracheal tubes in young children during general anesthesia. Anesthesiology 1997; 86: 627-31.

3 Murrat I. Cuffed tubes in children: a 3-year experience in a single institution (Letter). Paediatr Anaesth 2001; 11: 259-63.

4 Stock JG. Prolonged intubation and subglottic stenosis. BMJ 1966; 2: 826.

5 Holzki J. Laryngeal damage from tracheal intubation (Editorial). Paediatr Anaesth 1997; 7: 435-7.

6 Holzki J. Tubes with cuffs in newborn and young children are a risk! Remarks on the paper by T. Erb and F.J. Frei (Anaesthesist (2001) 50:395-400). (German). Anaesthesist 2002; 51: 321-3.

7 James I. Cuffed tubes in children (Editorial). Paediatr Anaesth 2001; 11: 259-63.

8 Motoyama EK. Tracheal intubation. In: Motoyama EK, Davis PJ (Eds.). Smith's Anesthesia for Infants and Children, 5 th ed. St. Louis: C.V. Mosby Company; 1990: 272-5.

9 Cole F. Pediatric formulas for the anesthesiologist. Am J Dis Child 1957; 94: 672-3.

10 Steward DJ, Lerman J. Techniques and procedures of pediatric anesthesia. In: Steward DJ, Lerman J (Eds.). Manual of Pediatric Anesthesia, 5th ed. New York: Churchill Livingstone; 2001: 69-127 (82).

11 Gould SJ, Howard S. The histopathology of the larynx in the neonate following endotracheal intubation. J Pathol 1985; 146: 301-11.

12 Ho AM, Aun CS, Karmakar MK. The margin of safety associated with the use of cuffed paediatric tracheal tubes. Anaesthesia 2002; 57: 169-82. 